\section{FAUNA OF THE HIGHLANDS.}

THIS handsome new addition to Mr. HarvieBrown's "Vertebrate Fauna of Scotland " maintains the high standard of excellence which has marked the preceding volumes. It is punctiliously accurate and at the same time picturesque and full of interest.

One of the authors, the

Rev. H. A. MacPherson, sacrificed himself too whole-heartedly to an enthusiasm for ornithology, and died in Igor at the age of forty-three, and Mr. Harvie-Brown has also to deplore the loss of another collaborator, $\mathrm{Mr}$. T. E. Buckley, who died in 1902. Of both these naturalists there are appropriate in memoriam sketches.

This volume deals specially with the western parts of the counties of Sutherland and Cromarty -west of the great "watershed"-and with similar portions of Rossshire and Inverness-shire down to the boundary of "Argyll." In the introductory matter we find terse physiographical accounts of Skye, the Ascrib Islands, Handa, Priest Island, and the coast of the mainland, designed to illustrate the most outstanding faunal feature of the area, namely, its isolation. $\mathrm{Mr}$. Lionel W. Hinxman contributes a brief account of the geology of the northwest Highlands, and there is another interesting section dealing with climatic and other changes, including those due to the hand of man. Few of these can be said to do man's intelligence much credit.

Mr. Harvie-Brown confesses that the chief interest of the area in question is the comparative poverty of its fauna. "The true faunal value lies in its isolation by sea and mountain ranges." "It appears to me to be almost the poorest and least favoured of our Scottish Faunal Areas, both as regards species and in its paucity of individuals of many of them." But it includes some old frequented haunts of some of our now rarer birds, it illustrates faunistic changes traceable to climatic changes, and it gives evidence of a keen

1 "A Fauna of the North-West Highlands and Skye." By J. A. Harvie Brown and H. A. MacPherson. Pp. civ+378; illustrated. (Edinburgh: David Douglas.) Price zos

NO. I 8,35 , VOL. $7 \mathrm{I}$ struggle for existence amid which some species are still advancing. What Mr. Harvie-Brown particularly seeks to show is that the hemmed-in nature of the area is a main reason for its faunal poverty; thus some of the more prominent land-features of the country, such as the long tongue of land of Ardnamurchan, act as deterrents to the advance of land birds from south to

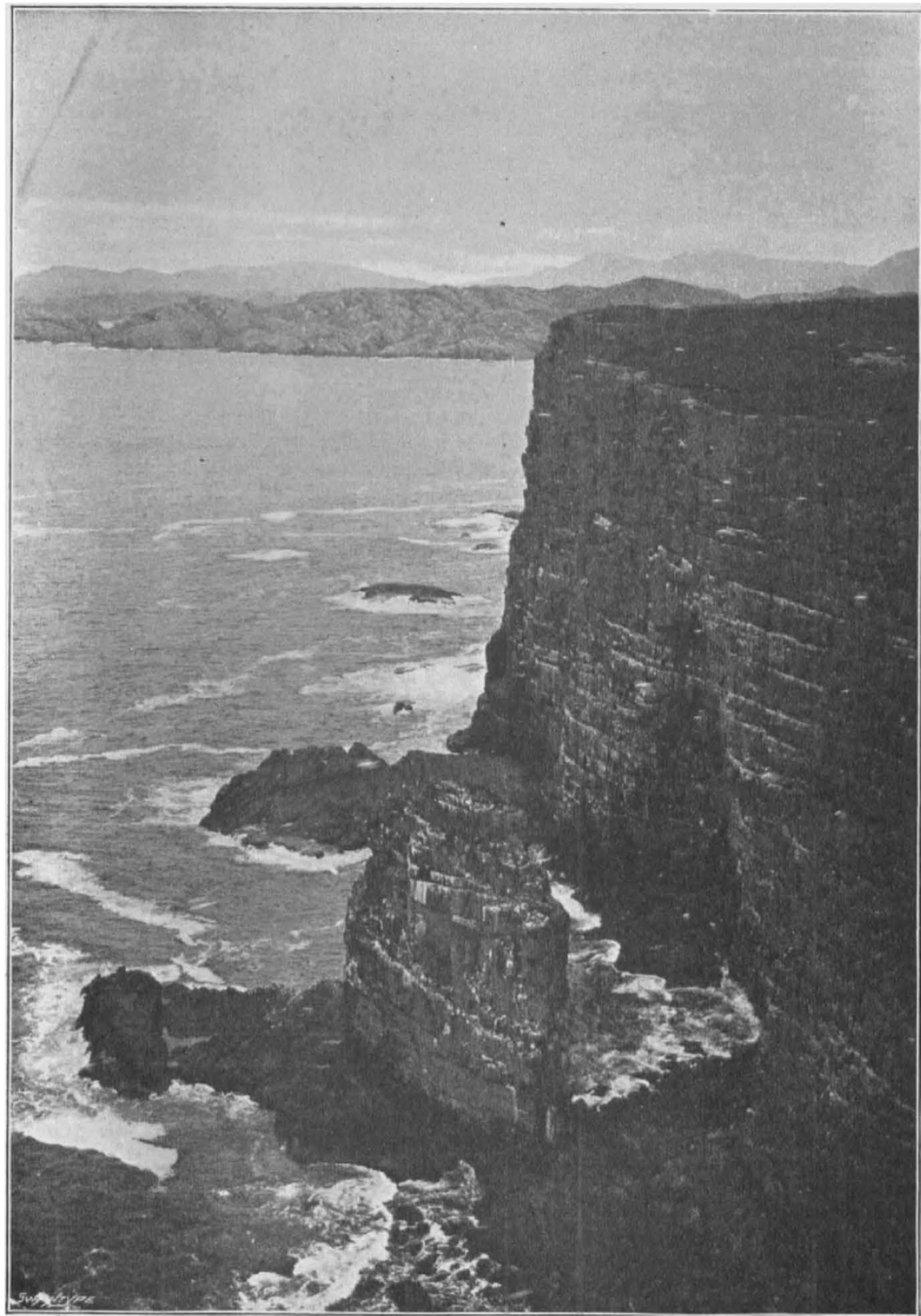

FIG. I.-Fulmar's first nesing-place on Handa (at small white $X$ ). From "A Fauna of the North-Wist Highlands and Skye."

The nature of the soil, the vegetation, the distribution and character of wooded areas, and the climatic conditions have also to be borne in mind, but Mr. Harvie-Brown has not done justice to himself or to his theme in his treatment of this aspect of the problem. Of course it is not given to everyone to be a Humboldt, but without attaining to his compre- 
hensiveness of outlook it would not have been difficult to improve the chapter on the "Faunal Position" of the area in question; and even in regard to the particular factors which Mr. Harvie-Brown emphasises in his interpretation of the faunistic peculiarities of the areas, his " argument,"' as he calls it, appears to us too jerky and elliptical to win conviction. But he gives some references to papers dealing with the physiographical conditions in some detail.

Turning to the list of mammals-which is somewhat mournful-we find that there is only one bat, the pipistrelle; the hedgehog, the lesser shrew, and the water-shrew are rare; the true wild cat still lingers; foxes, once very numerous, are now scarce; the marten, once abundant, is trembling in the balance between rarity and extinction; the polecat has become decidedly rare; a colony of badgers still persists ; the rabbit, introduced about $185^{\circ}$, is in many places taking a rapidlamentably rapid-hold of newly afforested grounds; and so on. The chief value of such information lies in the precision with which it records increase or decrease, e.g. of squirrel and polecat, within a term of years, and thus illustrates evolutionary processes going on around us.

We need hardly refer to the records of adder, lizard, and slow worm, of frog and toad, and two newts; but we may be allowed to note, without being captious, that the title on the back of the book and on the beautiful frontispiece, "A Fauna of the North-West Highlands and Skye," is somewhat too big for the volume, which deals with mammals, birds, reptiles, and amphibians, and no more.

The most entertaining part of the book is that which deals with the birds, in regard to which the authors speak from rich experience and with infectious enthusiasm. There is naturally enough a dominant note personnel, but it is always pleasant, even when the information given does not seem very important. Among the rare visitors we may mention the lesser whitethroat, the barred warbler, the nuthatch, the golden oriole, the great grey shrike, the waxwing, the rose-coloured pastor, the roller, the hoopoe, the osprey, the bittern, Pallas's sand-grouse, the rednecked phalarope, the great crested grebe, and the fulmar. Among the most interesting residents are the chough, the raven, the hen-harrier, the sea-eagle, the rock dove, and the ptarmigan. This section is rich in historical material, e.g. in regard to the starling, the golden eagle, the sea-

eagle, the osprey, the grey lag goose, and the fulmar. Apart from their historical interest, the notes on the birds are full of interesting observations, and some of the descriptions by the late Mr. MacPherson are fine pieces of picturesque writing. Mr. Harvie-Brown gives here and there an inkling of his strong views on bird protection; thus, "the Bird Acts require steady and relentless revision and change. The idea of saving trouble at Westminster and County Council and Sheriff Courts, by dividing Great Scotland into two divisions-north and southfor all species mentioned in these Acts, is absurd, and appears to me to be eminently calculated to defeat all useful purposes of the Acts." NO. I 835 , VOL. 7 I]
The book is beautifully got up and illustrated, and though, unfortunately, somewhat of a luxury, is sure to be welcomed by those who are interested in the wild life of Scotland. Its mood is one that will foster interest in open-air natural history, and the thoroughness of its lists should help to lessen the ruthless killing of supposed rarities.

J. A. T.

\section{A NATURALIST IN SARAWAK. ${ }^{1}$}

NEARLY forty years ago Dr. Beccari, the well known traveller-naturalist, made extensive journeys in Sarawak, but not until now has he published an account of his experiences; indeed, for this volume we have to thank the Ranee, H.H. Lady Brooke, who wisely urged Dr. Beccari to give the public the benefit of his knowledge, for, as she justly stated, the conditions have practically remained unchanged from times unknown.

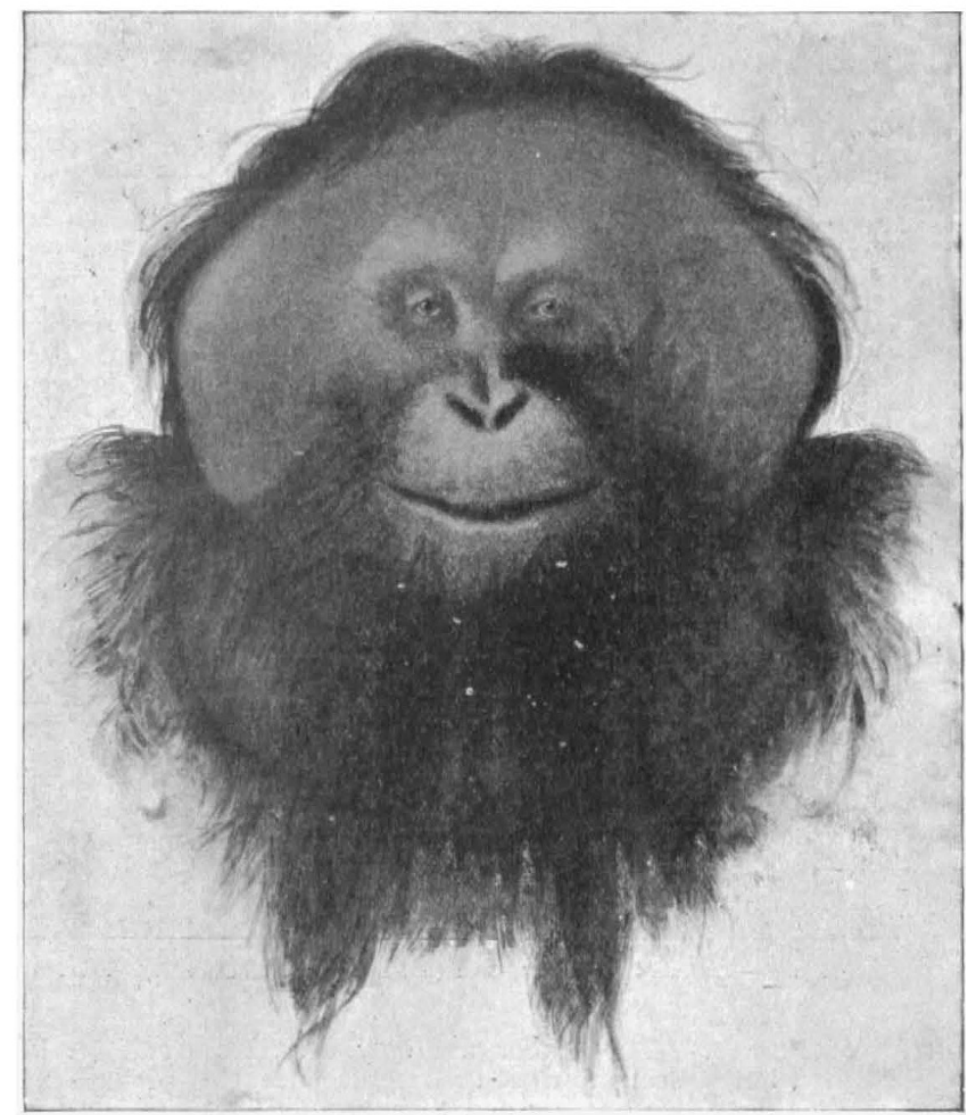

Fig. I.-Adult Male Mayas Tjaping. From "Wanderings in the Great Forests of Borneo"

Dr. Beccari collected in the land of the Land Dyaks, of the Sea Dyaks, and of the Kayans, not to mention less numerous peoples, and he gives a first-hand account of the people, their houses, dress, weapons, and ways. All this is very interesting reading, but there is little, if anything, that has not been recorded in Ling Roth's great compilation "The Natives of Sarawak and British North Borneo," or in the writings of more recent travellers. Indeed, it is the great fault of this book that the numerous contributions that have of late years been made to the natural history and 1 "Wanderings in the Great Forests of Borneo: Travels and Research ${ }^{\text {s }}$ of a Naturalist in Sarawak." By O. Beccari. "I ranslated by Dr. E. H Giglioli, and revised and edited by F. H. H. Guillemard. Po. xxiv +424 illustrated. (London: A. Constable and Co., 1904.) Price 16s. net 